\title{
EFFECTS OF SINTERING CONDITIONS ON MICROSTRUCTURE AND MECHANICAL PROPERTIES OF REACTIVE HOT PRESSED $\mathrm{TiB}_{2}-\mathrm{SiC}$ CERAMIC COMPOSITES
}

\author{
${ }^{\#}$ GUOLONG ZHAO*, CHUANZHEN HUANG**, NING HE*, HANLIAN LIU**, BIN ZOU** \\ *College of Mechanical and Electrical Engineering, Nanjing University of Aeronautics and Astronautics, \\ Nanjing 210016, P. R. China \\ **Key Laboratory of High-efficiency and Clean Mechanical Manufacture (Shandong University), \\ Ministry of Education, P. R. China \\ "E-mail: zhaogl@nuaa.edu.cn
}

Submitted April 8, 2016; accepted June 9, 2016

\begin{abstract}
Keywords: $\mathrm{TiB}_{2}-20$ wt. \% SiC, Reactive hot pressing, Sintering time, Sintering temperature
Reactive hot pressing (RHP) offers many advantages over the conventional hot pressing process. In this work, TiB $B_{2}-20$ wt. \% $\mathrm{SiC}$ ultra-high temperature ceramic composites were fabricated via RHP. The effects of sintering time $\left(1600-1700^{\circ} \mathrm{C}\right)$ and sintering temperature (30 - $60 \mathrm{~min})$, as well as the relationship between microstructure and mechanical properties, were investigated. For the investigated range of sintering conditions, the optimum comprehensive mechanical properties, i.e., flexural strength of $725 \mathrm{MPa}$, fracture toughness of $6.5 \mathrm{MPa} \cdot \mathrm{m}^{1 / 2}$ and hardness of $21.6 \mathrm{GPa}$, were achieved at $1700^{\circ} \mathrm{C}$ for 45 min. The good mechanical properties were attributed to small grain size and homogeneous microstructure. The sintering time and temperature had significant influences on the mechanical properties and microstructure of the composites. The flexural strength and hardness increased when the sintering time prolonged from $30 \mathrm{~min}$ to $45 \mathrm{~min}$, subsequently decreased with further increasing of time. The fracture toughness had the opposite trend. With increasing of the sintering temperature, both flexural strength and hardness increased. The high porosity resulted from the low temperature was responsible for the poor mechanical properties. Moderate sintering time and a higher sintering temperature would lead to higher mechanical properties.
\end{abstract}

\section{INTRODUCTION}

Titanium diboride $\left(\mathrm{TiB}_{2}\right)$ is well known as ultrahigh-temperature ceramics which have many attractive properties such as low density, high melting point, high hardness and great abrasive resistance and chemical inertness [1-3]. These unique properties make it a promising candidate material for several high-temperature structural applications such as cutting tools, armor, electrodes and wear-resistant parts. In addition, due to its good electrical conductivity, $\mathrm{TiB}_{2}$ ceramics can be cut into different shapes with electrical discharged machining (EDM). However, it is difficult to prepare $\mathrm{TiB}_{2}$ ceramics with relatively high density because of its low sinterability. Generally, a high sintering temperature (higher than $2200^{\circ} \mathrm{C}$ ) is required to prepare near fully dense monolithic $\mathrm{TiB}_{2}$ ceramics using the conventional hot pressing method. However, exaggerated grain growth resulted from such a high temperature is detrimental to its mechanical properties, which limits its structural applications. Besides, $\mathrm{TiB}_{2}$ has poor oxidation resistance, which deteriorates its performance at elevated temperatures. Therefore, the application of monolithic $\mathrm{TiB}_{2}$ ceramics is still limited.
As sintering aids, metallic additives such as nickel, iron and molybdenum can improve the sinterability of $\mathrm{TiB}_{2}$ ceramics. Nevertheless, metallic additives would be softened at elevated temperatures, resulting in degradation of mechanical properties. For example, when machining difficult-to-machine materials such as hardened steel and super alloys, $\mathrm{TiB}_{2}$ (with metallic additives) ceramic cutting tools are subjected to a high temperature [4]. The strength degradation may lead to catastrophic tool failure. Therefore, $\mathrm{TiB}_{2}$ ceramics with metallic additives is not suitable for high-temperature structural applications. Non-metallic additives such as TiC, TiN and $\mathrm{NbC}$ can significantly improve the sinterability of $\mathrm{TiB}_{2}$ ceramics [5-9]. Silicon carbide $(\mathrm{SiC})$ is characterized by high hardness, high melting point and excellent wear resistance. It has been confirmed that the addition of $\mathrm{SiC}$ particulates can promote densification of $\mathrm{TiB}_{2}$ ceramics [10-11]. In addition, $\mathrm{SiC}$ can also decelerate grain growth of $\mathrm{TiB}_{2}$ during sintering process, and improve oxidation resistance of $\mathrm{TiB}_{2}$ ceramics [12].

It is difficult to fabricate dense $\mathrm{TiB}_{2}-\mathrm{SiC}$ ceramic composites by the conventional hot pressing method using commercial $\mathrm{TiB}_{2}$ and $\mathrm{SiC}$ powders as raw materials. One reason is both $\mathrm{TiB}_{2}$ and $\mathrm{SiC}$ have low 
sinterability and dominant covalent bond. The other reason is a thin oxide layer (mainly $\mathrm{B}_{2} \mathrm{O}_{3}$ and $\mathrm{TiO}_{2}$ on the surface of commercial $\mathrm{TiB}_{2}$ powder, $\mathrm{SiO}_{2}$ on the surface of commercial SiC powder [13]) is inevitable, and it would promote grain and pore coarsening during hot pressing process. Except for hot pressing, several sintering methods such as hot isostatic pressing [14], high-frequency induction heating [15], combustion synthesis and dynamic densification [16], were used to fabricate $\mathrm{TiB}_{2}-\mathrm{SiC}$ ceramic composites. Even though relatively high mechanical properties were achieved using these methods, the cost was relatively high and the process was complex. Reaction sintering is an alternative method to fabricate $\mathrm{TiB}_{2}-\mathrm{SiC}$ ceramic composites, in which an in-situ reaction takes place and, $\mathrm{TiB}_{2}$ and $\mathrm{SiC}$ grains are synthesized. Reaction systems such as $\mathrm{TiH}_{2}-\mathrm{Si}-\mathrm{B}_{4} \mathrm{C}, \mathrm{TiH}_{2}-\mathrm{B}-\mathrm{SiC}-\mathrm{B}_{4} \mathrm{C}, \mathrm{SiC}-\mathrm{TiN}-\mathrm{B}$ and $\mathrm{TiH}_{2}-\mathrm{BN}-\mathrm{Si}$ have been employed to fabricate $\mathrm{TiB}_{2}-\mathrm{SiC}$ ceramic composites [17-19]. However, gases such as $\mathrm{H}_{2}$ or $\mathrm{N}_{2}$ were released during these reactions, which would form pores and deteriorate mechanical properties of the composites. Reactive hot pressing (RHP) is a promising method to fabricate $\mathrm{TiB}_{2}-\mathrm{SiC}$ ceramic composites with relatively high mechanical properties. RHP combines the advantages of both reaction sintering and hot pressing. Powdered materials can be densified at a lower temperature and materials with considerable mechanical properties can be produced by RHP. In addition, the microstructure and mechanical properties of the prepared composites can be tailored.

Therefore, in this paper, $\mathrm{TiB}_{2}-\mathrm{SiC}$ ceramic composites were fabricated via RHP using $\mathrm{Si}$, Ti and $\mathrm{B}_{4} \mathrm{C}$ as precursor powders. The effects of sintering conditions including sintering time and temperature on microstructure and mechanical properties were investigated in detail. The relationship between microstructure and mechanical properties at room temperature was studied. These works can be applied to aid materials engineering design for the development of new materials and quality assurance.

\section{EXPERIMENTAL}

\section{Materials preparation}

The $\mathrm{TiB}_{2}-\mathrm{SiC}$ ceramic composites were prepared via RHP according to the following reaction:

$$
\mathrm{Si}+2 \mathrm{Ti}+\mathrm{B}_{4} \mathrm{C}+x \mathrm{TiB}_{2} \rightarrow(2+x) \mathrm{TiB}_{2}+\mathrm{SiC}
$$

where $x$ is the amount of $\mathrm{TiB}_{2}$ powder (mol) used as raw material. In the present work, $x=0.3083$ was adopted based on calculations for maintaining the theoretical content of $\mathrm{SiC}$ at 20 wt. \%. The starting powders were $\mathrm{Si}, \mathrm{Ti}, \mathrm{B}_{4} \mathrm{C}$ and $\mathrm{TiB}_{2}$ powders. Their particle sizes and purities provided by the suppliers are listed in Table 1 . The stoichiometric amounts were mixed and ball-milled with tungsten carbide (WC) balls for 48 hours using ethanol as the medium. The ball-powder mass ratio was fixed to be 10:1. After dried and sieved through a 120 mesh sieve, the mixture was placed into a graphite die and reactively hot pressed at a heating rate of $50^{\circ} \mathrm{C} \cdot \mathrm{min}^{-1}$ under a pressure of $32 \mathrm{MPa}$ in vacuum. Different sintering time and temperatures were employed.

Table 1. Characteristics of the starting powders.

\begin{tabular}{cccl}
\hline Powder & Purity & $\begin{array}{c}\text { Particle } \\
\text { size }(\mu \mathrm{m})\end{array}$ & Supplier \\
\hline $\mathrm{Si}$ & $99.9 \%$ & 1.0 & $\begin{array}{l}\text { Shanghai st-nano science and } \\
\text { technology Co., Ltd }\end{array}$ \\
\hline $\mathrm{Ti}$ & $99.5 \%$ & 45.0 & $\begin{array}{l}\text { General research institute for } \\
\text { nonferrous metals }\end{array}$ \\
\hline $\mathrm{B}_{4} \mathrm{C}$ & $99.0 \%$ & 7.0 & $\begin{array}{l}\text { Jingangzuan boron carbide } \\
\text { Co., Ltd }\end{array}$ \\
\hline $\mathrm{TiB}_{2}$ & $98.5 \%$ & 1.3 & $\begin{array}{l}\text { Ningxia Machinery Research } \\
\text { Institute Co., Ltd }\end{array}$ \\
\hline
\end{tabular}

\section{Mechanical properties measurement}

The sintered samples were disk-shaped with $4.5 \mathrm{~mm}$ in thickness and $42 \mathrm{~mm}$ in diameter. The disks were sectioned into several testing bars with dimensions of $3 \mathrm{~mm} \times 4 \mathrm{~mm} \times 36 \mathrm{~mm}$ (height $\times$ width $\times$ length) with EDM. Subsequently the surfaces of the testing bars were polished using diamond slurries $(1.0 \mu \mathrm{m})$. The edges of all testing bars were chamfered to minimize stress concentration induced during the machining process. The flexural strength was measured in the static air using a three-point tester (INSTRON 8801, UK) with a support span of $30 \mathrm{~mm}$ and a loading rate of $0.5 \mathrm{~mm} \cdot \mathrm{min}^{-1}$. The load was applied parallel to the reactive hot pressing direction. The Vickers hardness was measured on the polished surface using a Vickers diamond pyramid indenter (HVS-50, China) with a static load of $196 \mathrm{~N}$ and a loading time of 15 seconds. The values of the fracture toughness $\left(\mathrm{K}_{\mathrm{IC}}\right)$ were calculated by equation reported by Fukuhara et al. [20].

\section{Characterization}

The phase composition was characterized by X-ray diffraction (XRD) (Hitachi RAX-10A-X, Japan). CuK $\mathrm{Cu}_{\alpha 1}$ radiation $(\lambda=1.54050 \AA)$ and a scan step of $0.2^{\circ} \mathrm{C} \cdot \mathrm{min}^{-1}$ were used. The microstructure of the samples sintered at different temperatures and time were observed using scanning electron microscopy (SEM) (Auriga-60, Germany) equipped with an energy-dispersive spectrometer (EDS) (Oxford, UK). The characterization of the composite, including the distribution of the grains, interfaces and compositions, was analyzed using a $200 \mathrm{kV}$ transmission electron microscopy (TEM) (JEM-2010F, Japan) equipped with an X-ray energy dispersive detector (EDAX, USA). 


\section{RESULTS AND DISCUSSION}

Phase identification

According to Equation 1, $\mathrm{TiB}_{2}-\mathrm{SiC}$ ceramic composites with different contents of $\mathrm{SiC}$ can be fabricated by adjusting the value of $\mathrm{x}$. This indicates that microstructure and mechanical properties of the composites can be tailored via RHP. In the present study, the theoretical mass fractions (wt. \%) of $\mathrm{TiB}_{2}$ and $\mathrm{SiC}$ were $80 \%$ and $20 \%$, respectively. Thus $\mathrm{TiB}_{2}$ and $\mathrm{SiC}$ can be treated as the matrix and secondary-phase particles, respectively. In this work, $\mathrm{TiB}_{2}$ powder used as raw material had a diluting effect on the reaction among $\mathrm{Si}, \mathrm{Ti}$ and $\mathrm{B}_{4} \mathrm{C}$. Excessive addition of $\mathrm{TiB}_{2}$ powder may inhibit the reaction process. Figure 1 shows the XRD pattern of the sample sintered at $1700^{\circ} \mathrm{C}$ for $30 \mathrm{~min}$. It indicates that $\mathrm{TiB}_{2}$ and $\mathrm{SiC}$ were successfully synthesized via RHP. No other byproducts with significant peak intensity were detected, demonstrating that $\mathrm{TiB}_{2}$ raw powder had no significant influence on the RHP process and the reaction was consistent with Equation 1.

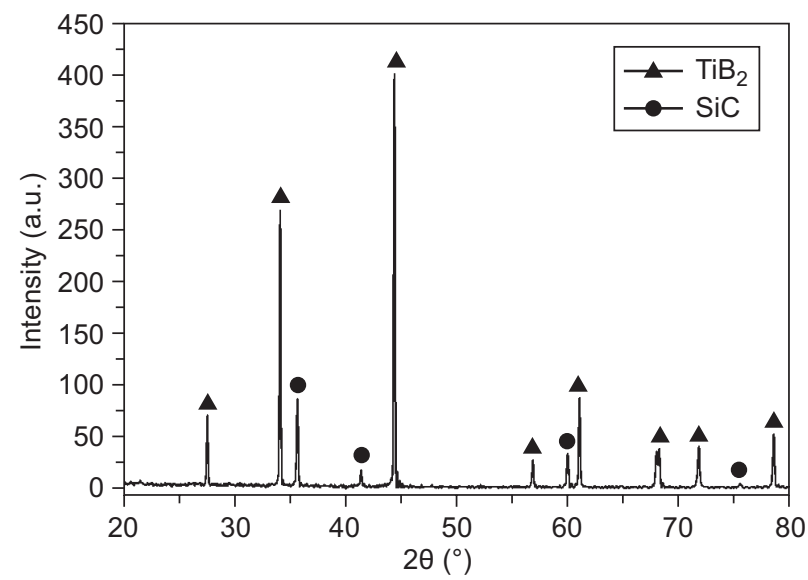

Figure 1. XRD pattern of the sample sintered at $1700^{\circ} \mathrm{C}$ for $30 \mathrm{~min}$.

\section{Microstructure}

Figure 2 shows the morphology of fractured surface of the composite fabricated at $1700^{\circ} \mathrm{C}$ for $30 \mathrm{~min}$. Two kinds of materials with different contrast are observed. The EDS analysis shown in Figure 3 demonstrates that the grey phase and dark grey phase are $\mathrm{TiB}_{2}$ and $\mathrm{SiC}$, respectively. It is seen from Figure 2 that the size of in-situ synthesized $\mathrm{SiC}$ grains is $0.5-1 \mu \mathrm{m}$ and that of $\mathrm{TiB}_{2}$ grains is $1.5-4 \mu \mathrm{m}$. However, the starting powders, especially $\mathrm{Ti}$ and $\mathrm{B}_{4} \mathrm{C}$ powders, have large particle sizes. This indicates that ceramic composites with small grain size could be fabricated via RHP using raw materials even with larger particle size. SiC grains mainly distribute in the interspaces among larger $\mathrm{TiB}_{2}$ grains and only few pores are observed, which result in a higher relative density. However, the microstructure of the composite is heterogeneous with $\mathrm{TiB}_{2}$ agglomerates, seen Figure 2.

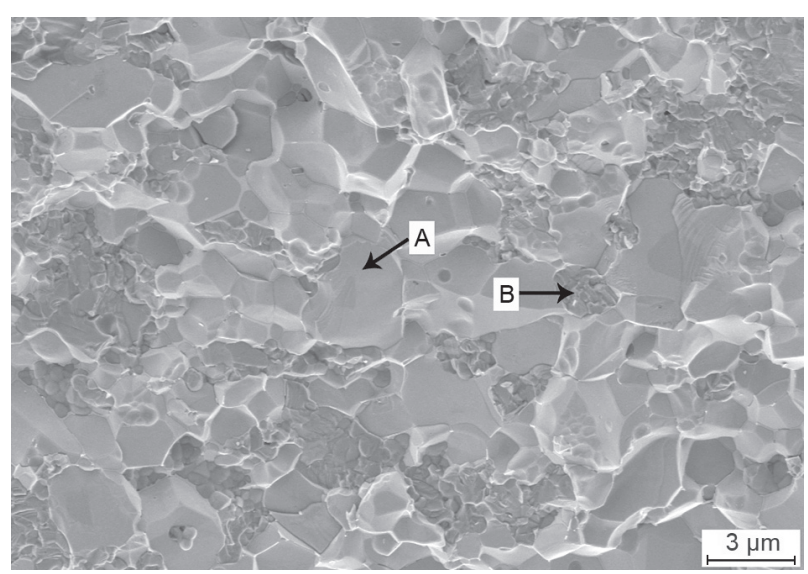

Figure 2. SEM image of fractured surface of the sample sintered at $1700^{\circ} \mathrm{C}$ for $30 \mathrm{~min}$.

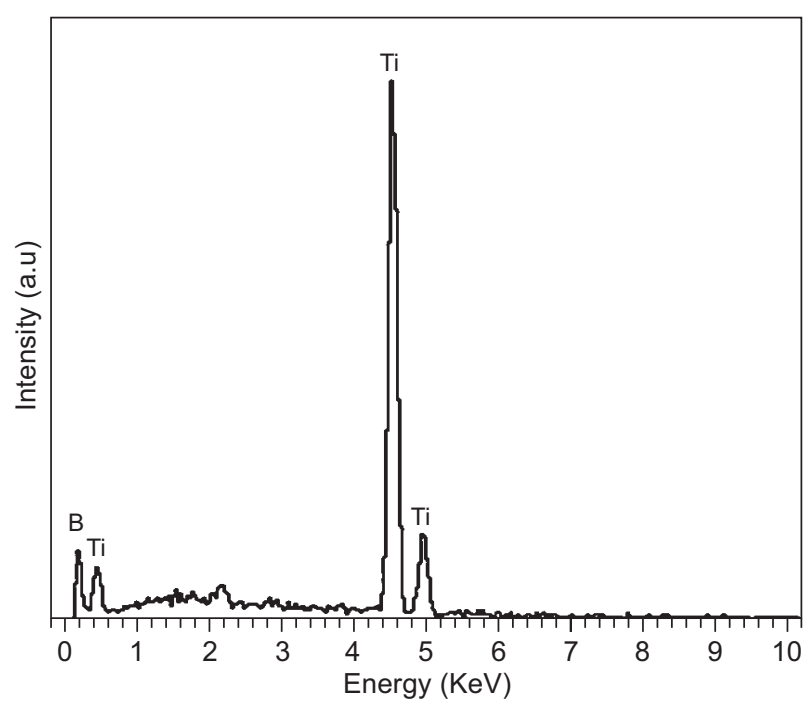

a) grey phase $A$

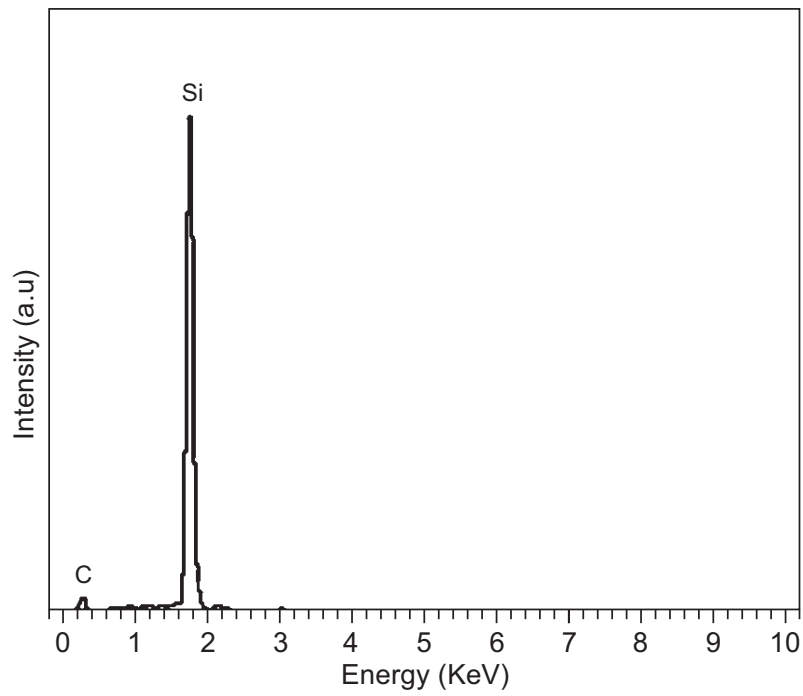

b) dark grey phase B

Figure 3. EDS patterns of the: a) grey phase A and b) dark grey phase B shown in Figure 2. 
It was assumed that the $\mathrm{TiB}_{2}$ agglomerates were associated with the large grain size of the starting Ti powder. In the reactive hot pressing process, the $\mathrm{B}$ atoms in $\mathrm{B}_{4} \mathrm{C}$ diffused into Ti sites and formed $\mathrm{TiB}_{2}$, and the $\mathrm{C}$ atoms diffused into $\mathrm{Si}$ sites and formed $\mathrm{SiC}$, respectively. The diffusion rate of $\mathrm{B}$ and $\mathrm{C}$ was faster than that of $\mathrm{Ti}$ and $\mathrm{Si}$. Thus the $\mathrm{TiB}_{2}$ agglomerates possessed the feature of the large particle size of the starting Ti powder. This can also explain $\mathrm{SiC}$ grains possessed the feature of the small particle size of the starting Si powder. Therefore, $\mathrm{TiB}_{2}-\mathrm{SiC}$ ceramic composites with fine and homogeneous microstructure, i.e., small grain size and all phases have well distributions could be achieved by using starting powders with smaller particle size and better uniformity of mixing. Then mechanical properties of the composite would be improved significantly.

For high-temperature applications such as cutting tools, ceramic composites must exhibit high strength at elevated temperatures. Therefore, any phases with low melting points must not present in the composites. It is well acknowledged that the grain boundaries and triple grain junctions have prominent effect on the mechanical behavior of ceramic composites, especially at elevated temperatures. For example, Zou et al. studied the high-temperature mechanical properties of $\mathrm{TiB}_{2}-$ -TiC-based ceramic composites [21]. It was found that softening of $\mathrm{Ni}$ distributed at both grain boundaries and triple grain junctions accelerated strength degradation at elevated temperatures. Loehman et al. investigated the degradation mechanisms of $\mathrm{ZrB}_{2}-\mathrm{SiC}$ ceramic material at elevated temperatures [22]. It revealed that softening of the impurities (glass phase) distributed at the grain boundaries resulted in the strength degradation. For ceramic composites without metallic additives, impurities are mainly derived from two approaches, i.e., impurities from the raw materials and contaminations induced during the preparation process. An oxygen rich layer (mainly $\mathrm{B}_{2} \mathrm{O}_{3}, \mathrm{TiO}_{2}$ or $\mathrm{ZrO}_{2}$ ) is usually present on surfaces of the commercial transition metal borides

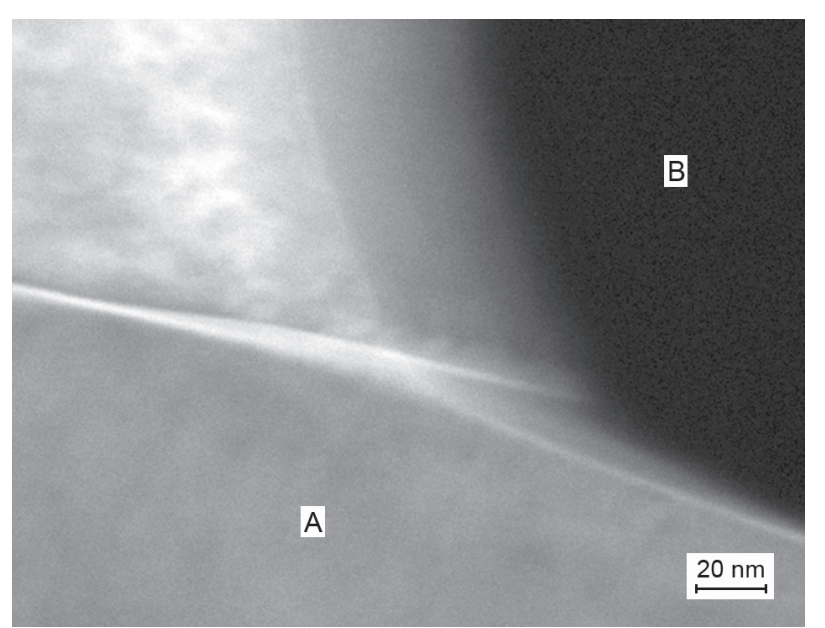

Figure 4. STEM image of the TiB2-SiC ceramic composite fabricated at $1700^{\circ} \mathrm{C}$ for $30 \mathrm{~min}$. powders such as $\mathrm{TiB}_{2}$ and $\mathrm{ZrB}_{2}$ powders. These oxides would result in the formation of amorphous phase with low melting points. In addition, it is unavoidable to induce impurities during the preparation process, especially the mixing process of starting powders. Figure 4 shows a scanning TEM image of the $\mathrm{TiB}_{2}-\mathrm{SiC}$ ceramic composite fabricated at $1700^{\circ} \mathrm{C}$ for $30 \mathrm{~min}$. It reveals that both the grain boundaries and triple grain junctions are clean and free from any impurities. Equation 1 is an exothermic reaction which released lots of heat, and temperature of the materials increased substantially. As a consequence, impurities with low melting points vaporized, resulting in clean grain boundaries and triple grain junctions. The EDS spectrums shown in Figure 5 reveal that the grey and dark phases are $\mathrm{TiB}_{2}$ and $\mathrm{SiC}$, respectively. The $\mathrm{Cu}$ peaks in Figure 5 are resulted from the TEM copper grid during preparation process of

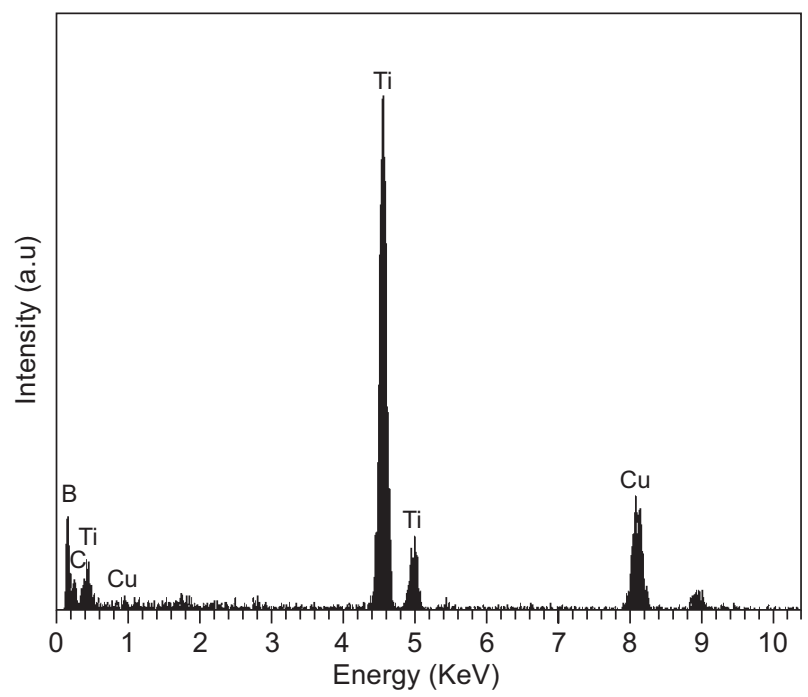

a) point $\mathrm{A}$

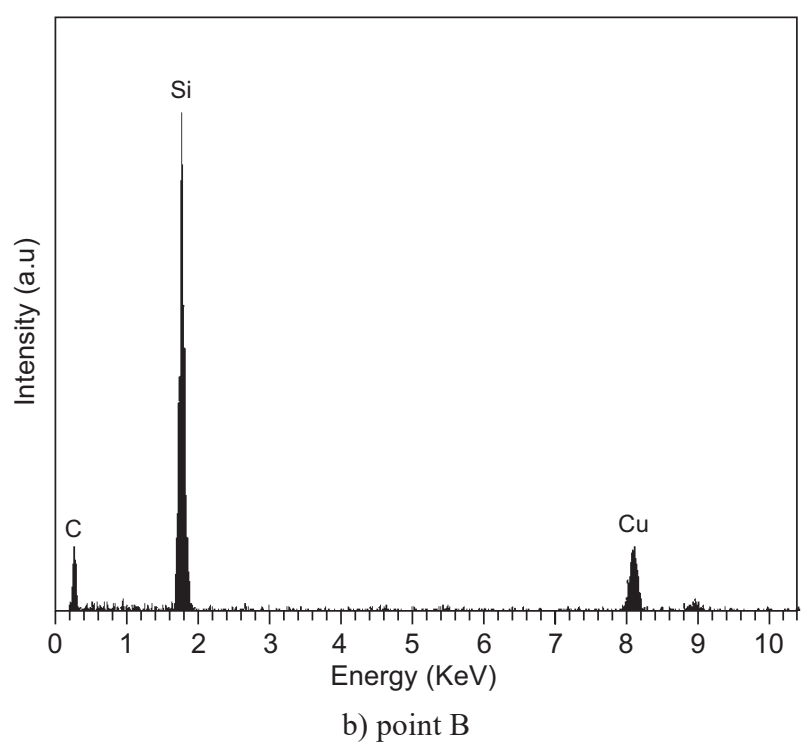

Figure 5. EDS spectrums of: a) point $\mathrm{A}$ and $\mathrm{b}$ ) point $\mathrm{B}$ in Figure 4. 
TEM sample by focused ion beam (FIB) method. Figure 6 shows HRTEM image of the $\mathrm{TiB}_{2} / \mathrm{SiC}$ grain boundary, which further presents a clean grain boundary. Such clean boundaries would be conductive to high strength retention at elevated temperatures, and make the ceramic composites suitable for high-temperature applications.

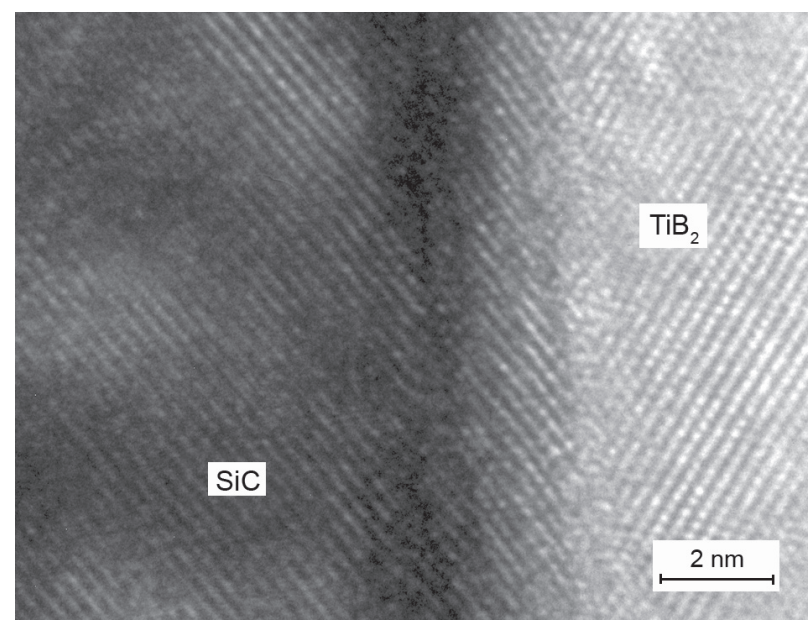

Figure 6. HRTEM image of the $\mathrm{TiB}_{2} / \mathrm{SiC}$ grain boundary.

Effect of sintering time on the mechanical properties and microstructure

Sintering is an important step in the fabrication process of ceramic composites, which can significantly affect the mechanical properties and microstructure of materials. Generally, the higher pressure applied, the better densification and higher mechanical properties would be achieved. In this work, the pressure was fixed at $32 \mathrm{MPa}$, which was the maximum capacity of the sintering instrument. Figure 7 shows the effect of sintering time on the mechanical properties including flexural strength, fracture toughness and hardness of $\mathrm{TiB}_{2}-\mathrm{SiC}$ ceramic composites fabricated at $1700^{\circ} \mathrm{C}$. Both flexural strength and hardness showed an remarkable

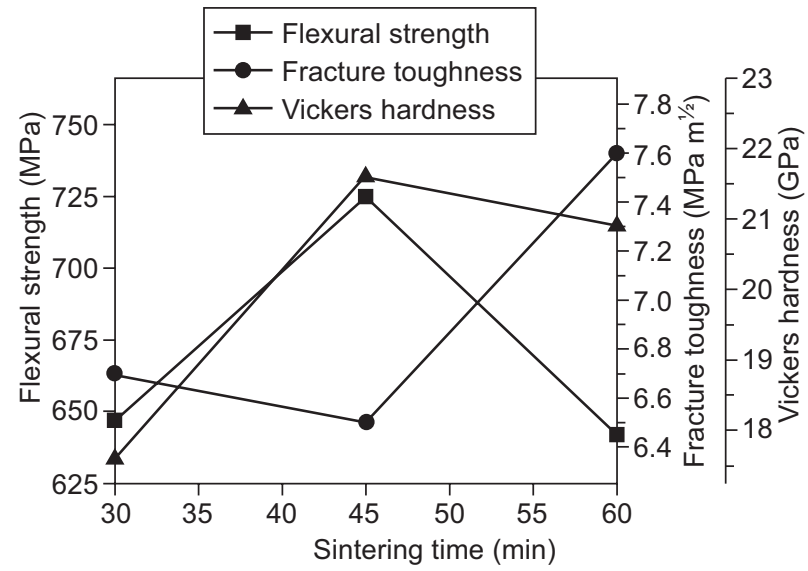

Figure 7. Effect of sintering time on the mechanical properties of $\mathrm{TiB}_{2}-\mathrm{SiC}$ ceramic composites. increase when the sintering time increased from $30 \mathrm{~min}$ to $45 \mathrm{~min}$, subsequently decreased with further increase of time. The fracture toughness showed a slight reduction, and then a significant increment over the same time range. For the investigated range of sintering time, the $\mathrm{TiB}_{2}-\mathrm{SiC}$ ceramic composite sintered for $45 \mathrm{~min}$ possessed optimum comprehensive mechanical properties, i.e., a flexural strength of $725 \mathrm{MPa}$, a fracture toughness of $6.5 \mathrm{MPa} \cdot \mathrm{m}^{1 / 2}$ and a hardness of $21.6 \mathrm{GPa}$, respectively.

It is well known that microstructure has pronounced influence on the mechanical properties of ceramic composites. SEM images of the fractured and polished surfaces of the $\mathrm{TiB}_{2}-\mathrm{SiC}$ ceramic composites sintered at $1700^{\circ} \mathrm{C}$ for $45 \mathrm{~min}$ and $60 \mathrm{~min}$ are shown in Figure 8 and Figure 9, respectively. As shown in Figure 8a, the grain size is $0.5-3 \mu \mathrm{m}$, which is smaller than that of the composite sintered for $30 \mathrm{~min}$. Figure $8 \mathrm{~b}$ shows that $\mathrm{SiC}$ grains distribute in the $\mathrm{TiB}_{2}$ matrix uniformly, presen-ting a homogeneous microstructure. The fine grains and the homogeneous microstructure improved the flexural strength. Very few pores can be observed from both the fractured and the polished surfaces, indicating the composite possesses a high

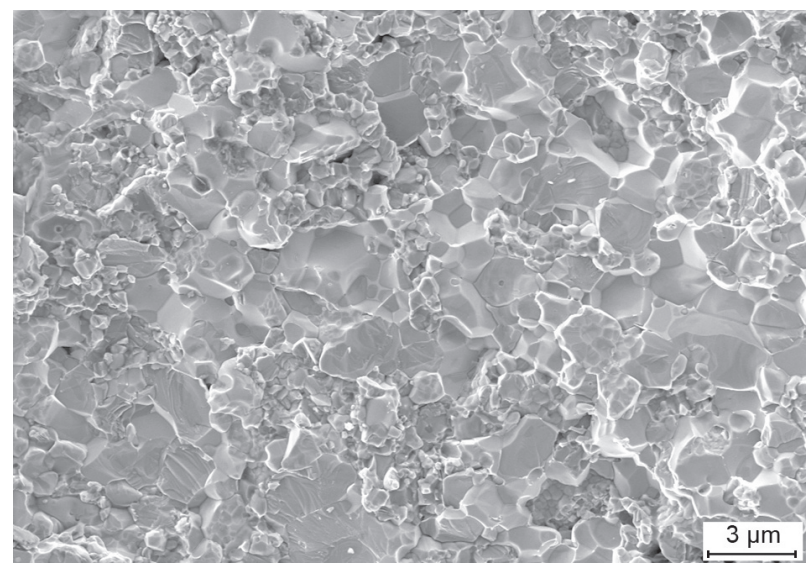

a) fractured surface

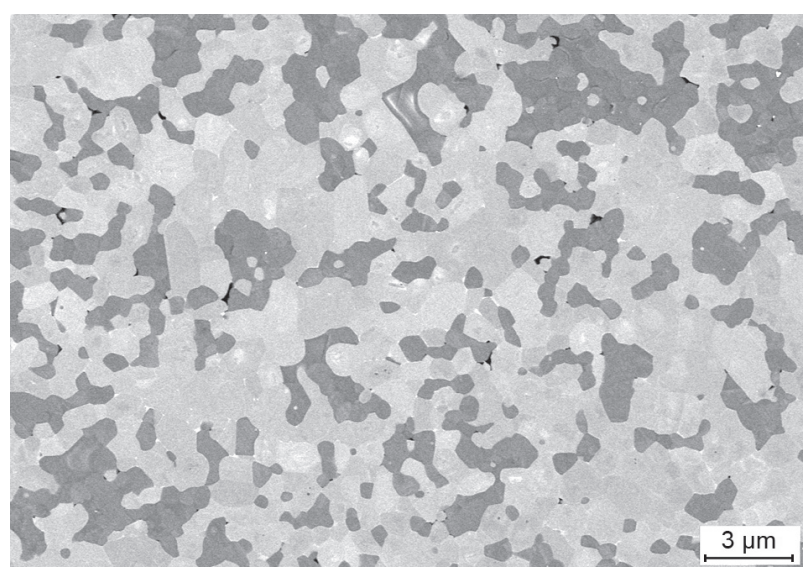

b) polished surface

Figure 8. SEM images of the: a) fractured and b) polished surfaces of the composite sintered for $45 \mathrm{~min}$. 
density, which improved the hardness. During the sintering process, grain rearrangement and pore reduction took place, producing a densified ceramic compact. An investigation conducted by Henrich et al. revealed that densification rate of ceramics was greatly enhanced by grain rearrangement during sintering [23]. Therefore, moderate sintering time is conductive to the homogeneous microstructure and relatively high flexural strength and hardness. However, with further increasing of the sintering time (from 45 to $60 \mathrm{~min}$ ), the grain size increased substantially, seen Figure 9. Thus, the flexural strength reduced, which is consistent with Ref. [24]. In addition, flexural strength reduces exponentially with the residual porosity increases for ceramic composites. The $\mathrm{TiB}_{2}-\mathrm{SiC}$ ceramic composite sintered for $60 \mathrm{~min}$ had a relatively high residual porosity see Figure 9a, which also leads to the substantial strength reduction. The fracture toughness increased from $6.5 \mathrm{MPa} \cdot \mathrm{m}^{1 / 2}$ to $7.6 \mathrm{MPa} \cdot \mathrm{m}^{1 / 2}$ when the sintering time increased form $45 \mathrm{~min}$ to $60 \mathrm{~min}$. The increase of fracture toughness is attributed to two reasons. Firstly, the cracks were pinned by the residual pores. For crack propagation, more energy was consumed, resulting in

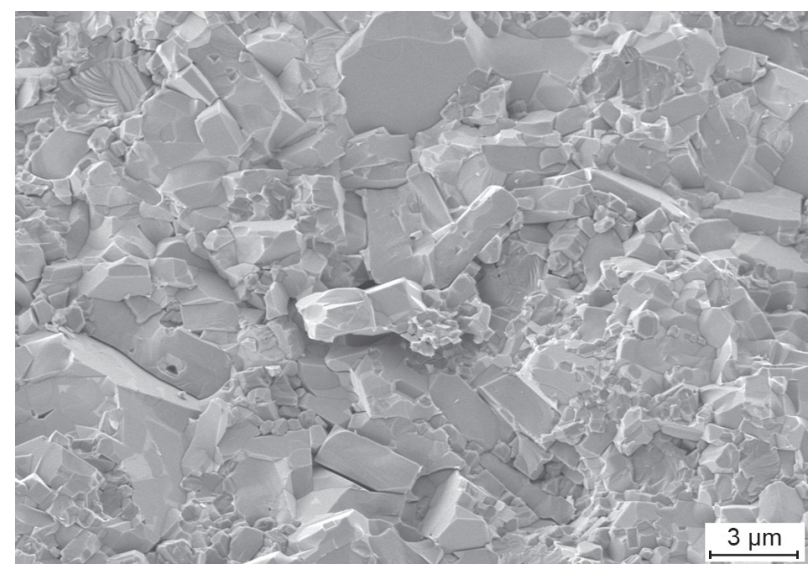

a) fractured surface

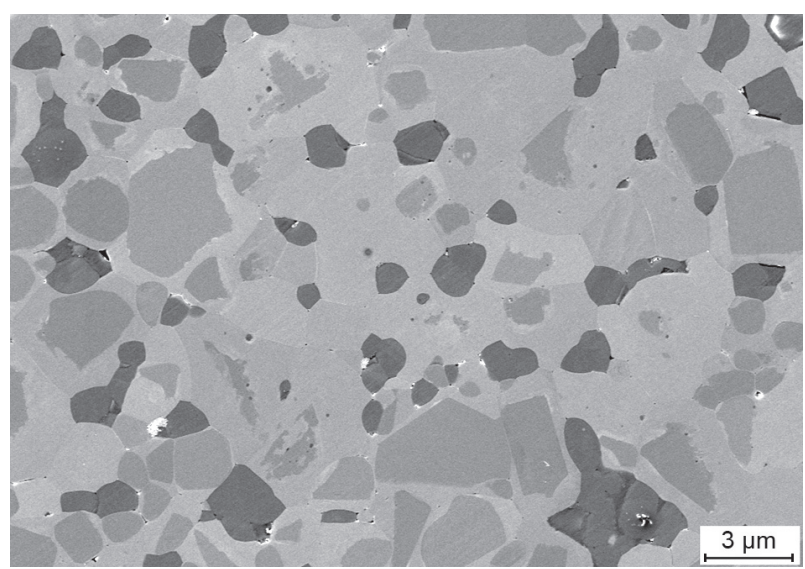

b) polished surface

Figure 9. SEM images of the: a) fractured and b) polished surfaces of the composite sintered for $60 \mathrm{~min}$. a high fracture toughness. Secondly, the main fracture mode is intergranular fracture, as shown in Figure 9a. The residual pores induced weak grain boundary which was conductive to crack deflection. Because the propagation path was deflected, more fracture energy was consumed, resulting in a high fracture toughness.

Effect of sintering temperature on the mechanical properties and microstructure

The effect of sintering temperature on the mechanical properties of $\mathrm{TiB}_{2}-\mathrm{SiC}$ ceramic composite sintered for $45 \mathrm{~min}$ is shown in Figure 10. Both the flexural strength and the hardness increased as the sintering temperature increased from $1600^{\circ} \mathrm{C}$ to $1700^{\circ} \mathrm{C}$. The fracture toughness decreased as the sintering temperature increased from $1600^{\circ} \mathrm{C}$ to $1650^{\circ} \mathrm{C}$, and then increased with further increase of the sintering temperature. For the investigated range of sintering temperatures, the $\mathrm{TiB}_{2}-\mathrm{SiC}$ ceramic composite sintered at $1700^{\circ} \mathrm{C}$ possessed optimum comprehensive mechanical properties. From Figure 10 , it is believed that the comprehensive mechanical properties will further increase if a higher sintering temperature is applied. However, the increase of temperature is restricted by the instrument. The morphologies of $\mathrm{TiB}_{2}-\mathrm{SiC}$ ceramic composite sintered at $1600^{\circ} \mathrm{C}$ are shown in Figure 11. The grain size is $0.5-3 \mu \mathrm{m}$, and no abnormal large grains are observed, which is attributed to the low sintering temperature. However, a number of pores are observed, see Figure 11a. The pores are mainly distributed at grain boundaries. The high porosity leads to decreased flexural strength and hardness. As shown in Figure 11b, some grains dropped off from the polished surface, indicating a low boundary strength. Therefore, for $\mathrm{TiB}_{2}-\mathrm{SiC}$ ultra-high temperature ceramic composites, low sintering temperature would lead to high porosity and poor mechanical properties.

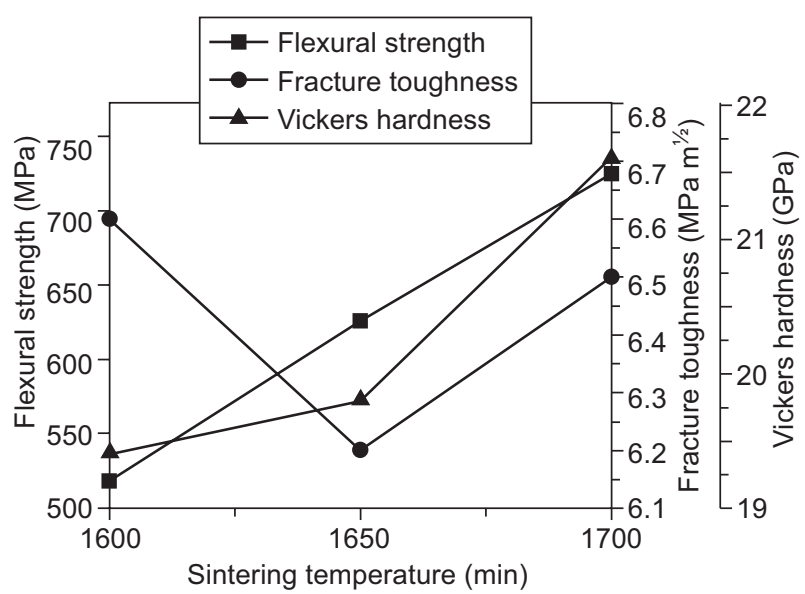

Figure 10. Effect of sintering temperature on the mechanical properties of $\mathrm{TiB}_{2}-\mathrm{SiC}$ ceramic composites. 


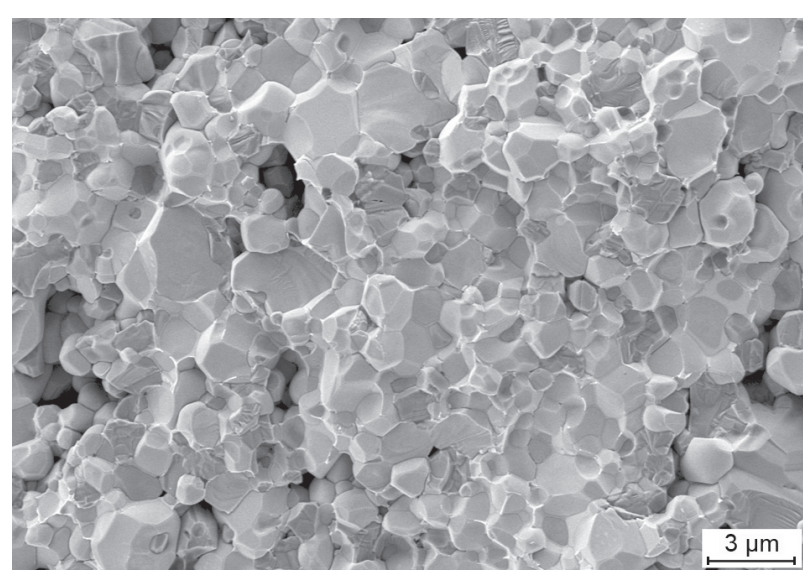

a) fractured surface

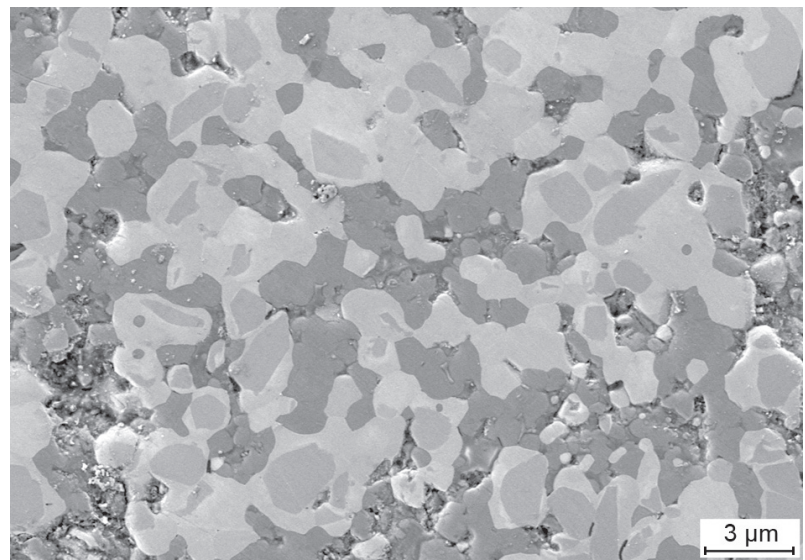

b) polished surface

Figure 11. SEM images of the: a) fractured and b) polished surfaces of the composite sintered at $1600^{\circ} \mathrm{C}$.

\section{CONCLUSIONS}

$\mathrm{TiB}_{2}-20$ wt. \% SiC ceramic composites were fabricated via RHP process under $32 \mathrm{MPa}$ in vacuum under different sintering conditions. The composite synthesized at $1700^{\circ} \mathrm{C}$ for $30 \mathrm{~min}$ was characterized by small grain size and heterogeneous microstructure. The STEM and HRTEM analyses indicated that the interfaces and triple junctions of the composite were free from additional boundary phases. Sintering time and sintering temperature had significant influences on the microstructure and mechanical properties of the ceramic composites. For the investigated range of sintering conditions, the $\mathrm{TiB}_{2}-\mathrm{SiC}$ ceramic composite fabricated at $1700^{\circ} \mathrm{C}$ for $45 \mathrm{~min}$ possessed the optimum comprehensive mechanical properties with flexural strength of $725 \mathrm{MPa}$, fracture toughness of $6.5 \mathrm{MPa} \cdot \mathrm{m}^{1 / 2}$ and hardness of $21.6 \mathrm{GPa}$. Moderate sintering time and a higher sintering temperature would be conductive to higher mechanical properties. This work offers a promising method for fabricating ultra-high temperature ceramic composites with relatively high mechanical properties.
Acknowledgements

This work is supported by the National Natural Science Foundation of China (51175305).

\section{REFERENCES}

1. Fahrenholtz W.G., Wuchina E.J., Lee W.E., Zhou Y.C. (2014): Ultra-high temperature ceramics: materials for extreme environment applications. $1^{\text {st }}$ ed. John Wiley \& Sons, Inc.

2. Yadawa P.K. (2011): Ultrasonic characterization of ceramic material titanium diboride. Ceramics-Silikáty, 55, 127-133.

3. Demirskyi D., Cheng J., Agrawal D., Ragulya A. (2013): Densification and grain growth during microwave sintering of titanium diboride. Scripta Materialia, 69, 610-613. doi:10.1016/j.scriptamat.2013.07.012

4. EL-Wardany T.I., Mohammed E., Elbestawi M.A. (1996): Cutting temperature of ceramic tools in high speed machining of difficult-to-cut materials. International Journal of Machine Tools and Manufacture, 36, 611-634. doi: 10.1016/0890-6955(95)00043-7

5. Wang D.Y., Wang H.H., Sun S.C., Zhu X.P., Tu G.F. (2014): Fabrication and characterization of $\mathrm{TiB}_{2} / \mathrm{TiC}$ composites. International Journal of Refractory Metals and Hard Materials, 45, 95-101. doi:10.1016/j.ijrmhm.2014.03.004

6. Zou B., Huang C.Z., Song J.P., Liu Z.Y., Liu L., Zhao Y. (2012): Mechanical properties and microstructure of $\mathrm{TiB}_{2}$ $\mathrm{TiC}$ composite ceramic cutting tool material. International Journal of Refractory Metals and Hard Materials, 35, 1-9. doi:10.1016/j.ijrmhm.2012.02.011

7. Yang Z.L., Ouyang J.H., Liu Z.G., Liang X.S., Wang Y.J. (2013): Microstructure and tribological properties of reactive hot pressed $\mathrm{TiN}^{-\mathrm{TiB}_{2}}$ composites incorporated with or without $\mathrm{MoSi}_{2}$ from room temperature to $800^{\circ} \mathrm{C}$. Wear, 301, 641-647. doi:10.1016/j.wear.2013.01.012

8. Yang Z. L., Liu Z. G., Ouyang J. H., Zhou Y., Wang Y. J., Sloof W. G. (2013): Synthesis route and mechanical properties of reactive hot pressed TiN-TiB 2 ceramics. International Journal of Refractory Metals and Hard Materials, 41, 54-59. doi:10.1016/j.ijrmhm.2013.02.001

9. Demirskyi D., Sakka Y., Vasylkiv O. (2015): High-temperature reactive spark plasma consolidation of $\mathrm{TiB}_{2}-\mathrm{NbC}$ ceramic composites. Ceramics International, 41, 1082810834. doi:10.1016/j.ceramint.2015.05.022

10.King D.S., Fahrenholtz W.G., Hilmas G.E. (2013): Silicon carbide-titanium diboride ceramic composites. Journal of the European Ceramic Society, 33, 2943-2951. doi: 10.1016/j.jeurceramsoc.2013.03.031

11. Bucevac D., Krstic V. (2012): Microstructure-mechanical properties relations in $\mathrm{SiC}^{-\mathrm{TiB}_{2}}$ composite. Materials Chemistry and Physics, 133, 197-204. doi:10.1016/j. matchemphys.2012.01.007

12.Zhao G.L., Huang C.Z., Liu H.L., Zou B., Zhu H.T., Wang J. (2014): Microstructure and mechanical properties of hot pressed $\mathrm{TiB}_{2}-\mathrm{SiC}$ composite ceramic tool materials at room and elevated temperatures. Materials Science and Engineering A, 606, 108-116. doi:10.1016/j.msea. 2014.03.084

13.Basu B., Raju G.B., Suri A.K. (2006): Processing and 
properties of monolithic $\mathrm{TiB}_{2}$ based materials. International Materials Reviews, 51, 352-374. doi:10.1179/ 174328006X102529

14.Degui Z., Shikai L., Xiandong Y., Liu Y., Chuanchun X., Haoming Z., Jianyong Z. (1999): In-situ HIP synthesis of $\mathrm{TiB}_{2} / \mathrm{SiC}$ ceramic composites. Journal of Materials Processing Technology, 89-90, 457-461. doi:10.1016/S09240136(99)00137-5

15.Chen H.B., Wang Z., Wu Z.J. (2014): Investigation and characterization of densification, processing and mechanical properties of $\mathrm{TiB}_{2}-\mathrm{SiC}$ ceramics. Materials \& Design, 64, 9-14. doi:10.1016/j.matdes.2014.07.012

16.Hoke D.A., Kim D.K., LaSalvia J.C., Meyers M.A. (1996): Combustion synthesis/dynamic densification of a $\mathrm{TiB}_{2}-$ $\mathrm{SiC}$ composite. Journal of the American Ceramic Society, 79, 177-182. doi:10.1111/j.1151-2916.1996.tb07896.x

17.Zhang G.J., Jin Z.Z., Yue X.M. (1995): Reaction synthesis of $\mathrm{TiB}_{2}-\mathrm{SiC}$ composites from $\mathrm{TiH}_{2}$. Materials Letters, 25, 97-100. doi:10.1016/0167-577X(95)00159-X

18.Ran S.L., Van der Biest O., Vleugels J. (2011): In situ platelet-toughened $\mathrm{TiB}_{2}-\mathrm{SiC}$ composites prepared by reactive pulsed electric current sintering. Scripta Materialia, 64, 1145-1148. doi:10.1016/j.scriptamat.2011.03.015

19. Tani T., Wada S. (1990): SiC matrix composites reinforced with internally-synthesized $\mathrm{TiB}_{2}$. Journal of Materials
Science, 25, 157-160. doi:10.1007/BF00544201

20.Fukuhara M., Fukazawa K., Fukawa A. (1985): Physical properties and cutting performance of silicon nitride ceramic. Wear, 102, 195-210. doi:10.1016/0043-1648(85) 90218-2

21.Zou B., Ji W.B., Huang C.Z., Xu K.T., Li S.S. (2014): Degradation of strength properties and its fracture behaviour of $\mathrm{TiB}_{2}-\mathrm{TiC}$-based composite ceramic cutting tool materials at the high temperature. International Journal of Machine Tools and Manufacture, 47, 1-11. doi:10.1016/j. ijrmhm.2014.06.013

22.Loehman R., Corral E., Dumm H.P., Kotula P., Tandon R. (2006): Ultra high temperature ceramics for hypersonic vehicle applications. Sandia Report, 2006-2925, 1-45.

23. Henrich B., Wonisch A., Kraft T., Moseler M., Riedel H. (2007): Simulations of the influence of rearrangement during sintering. Acta Materialia, 55, 753-762. doi:10.1016/j.actamat.2006.09.005

24. Yin Z.B., Huang C.Z., Zou B., Liu H.L., Zhu H.T., Wang J. (2013): Preparation and characterization of $\mathrm{Al}_{2} \mathrm{O}_{3} / \mathrm{TiC}$ micro-nano-composite ceramic tool materials. Ceramics International, 39, 4253-4262. doi:10.1016/j. ceramint.2012. 10.277 